\title{
Psycho-spatial predictors of hazardous drinking among motor drivers in Ibadan, Nigeria: Implications for preventing vehicular accidents
}

\author{
Gboyega E. Abikoye \\ Department of Clinical Psychology, Faculty of Clinical Sciences, College of Health Sciences, Niger Delta University, Nigeria
}

\begin{abstract}
Aims: The study examined the roles of selected psychological, demographic and environmental variables in predicting hazardous drinking for both commercial drivers and private drivers.
\end{abstract}

Design: The study was a cross-sectional survey.

Setting: Data were collected at motor parks, auto workshops and car wash centers across the metropolis of Ibadan, Nigeria.

Participants: A convenience sample of 566 drivers was recruited (241 commercial and 325 private drivers). Most drivers were male, and the mean age of the total sample was 35.70 years ( \pm 8.62 years).

Measurements: The Alcohol Use Disorders Identification Test (AUDIT) was used to measure hazardous drinking. Psychological variables included standardized measures of perceived drinking norms and optimistic bias. Demographic variables included age, sex, education, marital status, employment status and income. Environmental variables included proximity to alcohol vendors or selling points and neighborhood density.

Findings: About $45 \%$ of commercial drivers and $25 \%$ of private drivers reported hazardous levels of alcohol consumption. Hazardous drinking was predicted by age, education, income, proximity to alcohol outlets, neighborhood density, optimistic bias and perceived drinking norms even when all variables were included in the regression model. These variables accounted for a substantial proportion of variance in predicting hazardous drinking.

Conclusions: Psychological, environmental and demographic variables are important in understanding hazardous drinking among drivers and should be incorporated into intervention for reducing drivers' hazardous drinking, including drinking and driving.

Alcohol is widely consumed around the world, and its misuse can have severe negative physical, social, psychological and economic consequences. Alcohol is the most commonly abused substance in Nigeria, with 56\% ever users and $14 \%$ recent (past year) users (Gureje et al., 2007). One of the problems associated with hazardous alcohol use is increased possibility of involvement in road traffic accidents, due to impaired judgement and/or higher probability that an individual will engage in other high-risk behaviors such as violating traffic regulations (Gururaj, 2004). Researchers have established a strong association between alcohol

Correspondence: Gboyega E. Abikoye, Department of Clinical Psychology, Faculty of Clinical Sciences, College of Health Sciences, Niger Delta University, Wilberforce Island, Bayelsa State, Nigeria

E-mail: ageabikoye@yahoo.com

Keywords: hazardous drinking, psycho-spatial variables, vehicular accidents, drivers, Nigeria 
use and road traffic accidents in Nigeria (Omolase, Afolabi, Omolase, \& Ihemedu, 20II; Owoaje, Amoran, Osemeikhain, \& Ohnoferi, 2005; Welcome \& Pereverzev, 20Iо; World Health Organization [WHO], 2009). In fact, Welcome and Pereverzev (20I0) reported that approximately $50 \%$ of accidents on Nigerian roads are related to alcohol use.

Despite the widely acknowledged association between drivers' hazardous alcohol use and road traffic accidents (WHO, 2009), the practice is still rampant in Nigeria. For example, Abiona, Aloba and Fatoye (2006) found that all their respondents (commercial drivers) were engaged in the use of commonly available alcoholic beverages in the vicinity of their various motor parks. Makanjuola, Oyeleke and Akande (2007) reported that the use of psychoactive substances, especially alcohol, was very common among long-distance vehicle drivers in Ilorin, Nigeria. In a study among commercial drivers in Nigeria by Omolase et al. (2OII), 32.2\% of respondents admitted to intake of alcohol prior to driving in the year preceding the study.

In a recent report (Global Actions on Harmful Drinking, 20II), the prevalence of drinking by commercial drivers in Nigeria (from Port Harcourt and Ile-Ife) was $67.2 \%$. Of those drivers, $47 \%$ were "heavy" users, I5.3\% were "moderate" users and $37.7 \%$ were occasional or "mild" users. In addition, between 60\% and 70\% of commercial drivers engage in drinking and driving, a habit linked to the pervasive perception and general notion that alcohol helps them to "shine their eyes" - that is, be alert while driving. In combination with other factors, hazardous alcohol use by drivers has contributed to the high rate of vehicular accidents in Nigeria. One of the reasons for the high rates of drinking and driving in Nigeria is that the country lacks a legal maximum blood alcohol concentration (BAC) (Welcome \& Pereverzev, 20I0). Furthermore, Nigeria has a single law against impaired driving under the country's Federal Traffic Code, which stipulates that all individuals who are under the influence of alcohol "to the extent as to be incapable of having proper control of the vehicle" shall be penalized. However, with no legal BAC it is impossible to prosecute an individual for impaired driving.

Due to the realization that road traffic accidents constitute a major cause of morbidity, mortality, disability and socio-economic loss, concerted efforts are being made in most countries of the world toward minimizing injuries and fatalities from alcohol-impaired driving. Many countries have introduced new legislation, intensified enforcement of drink-driving laws, and increased awareness and research efforts in alcohol-related issues. In Nigeria, effort has been made by government and the private sector to create public awareness, targeted at populations at risk, primarily commercial vehicle drivers. The police, the Federal Ministry of Health and some non-governmental organizations (NGOs) have also embarked upon mass mobilization and public media campaigns to educate drivers on the effects of alcohol on the human body and the importance of not drinking and driving. Unfortunately, not much has been done in terms of implementation and enforcement. Mechanisms for detecting drinkdriving and punishing offenders are not in place. Sale and marketing of alcohol is not regulated, and the various motor parks in the country typically contain alcohol-selling outlets in which drivers drink while their vehicles are being loaded. Alcohol manufacturers in Nigeria seem to be capitalizing on these apparent lapses in regulating alcohol sale and use, as they now offer their products in various sizes and shapes, making them readily affordable to everyone. Spirits now come conveniently and cheaply in small sachets and small bottles, while many vendors dispense assorted alcohol (branded and non-branded) with cups and polythene sachets.

One important psychological variable that has featured prominently in many forms of risky behavior is optimistic bias. Optimistic bias is commonly defined as the mistaken belief that one's chance of experiencing a negative event is lower (or a positive event higher) than that of one's peers. Based on health models such as the prototype/willingness model (Gibbons, Gerrard, \& Lane, 2003), if people underestimate their risk of experiencing a negative health outcome, they will be less likely to take precautions to prevent that outcome from occurring. Perceiving others as more at risk than oneself has been linked to greater likelihoods of engaging in detrimental behaviors (Scheier, Carver, \& Bridges, I994), such as hazardous drinking.

Another factor that may predict hazardous drinking among drivers is perceived drinking norms. The general definition of social influence is that health-related behavior is influenced by a person's social context. The behavioral social context can be represented by the behaviors of an individual's peers or family members (e.g., alcohol use) with whom the person interacts regularly, or by behaviors observed in a larger social environment such as the neighborhood in which a person lives. The normative social context is represented in an individual's perceptions about the acceptability of a 
behavior, such as alcohol use, derived from communications from network members, or by portrayals of behaviors in mass media such as television or movies (Brody, Flor, Hollett-Wright, \& Mccoy, I998). If a driver considers a behavior (i.e., alcohol use) as normal and appropriate for him or her, then the likelihood is high that he or she would be more likely to engage in the behavior.

The environment may also play a role. Theories of neighborhood influences (Coleman, I988; Shaw \& Mckay, I969; Wilson, I987) clearly demonstrate the overwhelming influence of neighborhood on human behavior. These influences are brought about through mediating paths such as local organizations, informal social control, residents' consensus on conventional norms, deviant peer groups, helping social network and parents' characteristics. Previous studies on the influence of neighborhood on alcohol use have demonstrated inconsistencies in their findings (Allison et al., I999; Case, I991; Karvonen \& Harja, I997). Some studies have found a strong connection between neighborhood influence and substance use. For example Crum, LillieBlanton and Anthony (1996) showed that residing in a disadvantaged neighborhood increased the likelihood that adolescents were offered various kinds of substances, including alcohol. Karvonen and Harja (I997) reported that dwelling in such a neighborhood increased the likelihood of developing heavy drinking patterns. In other studies, however, neighborhoods were found to have small effects compared with peer substance use (Abdelrahaman, Rodriguez, Ryan, French \& Wembaum, I998) or were found to have no effect at all on adolescent alcohol use (Allison et al., I999). There is a need, therefore, for more empirical investigation to unravel the seeming inconsistency surrounding the environmental association with alcohol use, especially by drivers.

Many studies have been conducted on hazardous alcohol use among different populations in Nigeria, especially students (Abikoye \& Adekoya, 20Iо; Abikoye \& Osinowo, 20II; Hibell et al., 2009; Siziya, Rudatsikira, \& Muula, 2009), and drivers (Aworemi, Abdul-Azeez, \& Olabode, 20ıо; Omolase et al., 20II; Owoaje et al., 2005; WHO, 2009). Major stakeholders have equally made some attempts at reducing the menace of hazardous drinking through mass mobilization and public media campaigns. But neither the rate of drink-driving nor that of vehicular accidents has decreased. In fact, it is estimated that deaths attributable to vehicular fatalities in low-income and middle-income countries, including Nigeria, will increase by as much as $80 \%$ by 2020 (WHO, 2004).

A review of the empirical literature indicates that little attention has been paid to important psychological and environmental factors that can influence hazardous drinking in Nigeria. For instance, the author is not aware of any alcoholfocused studies in Nigeria that investigated environmental factors such as neighborhood influence. It is also important to mention that most studies done in Nigeria on alcohol use among drivers have focused almost exclusively on commercial drivers. The reality, however, is that private car drivers also engage in hazardous drinking, but they have not been considered an at-risk population to be targeted for research attention and intervention by stakeholders.

There is a need, therefore, to also examine the extent to which private car drivers engage in hazardous drinking. Knowledge of the extent of hazardous drinking in this population and relevant psychological, environmental and socio-demographic predictors would be helpful for developing recommendations for planning and implementing intervention programmes in Nigeria.

\section{Research objectives}

This research focused on two main objectives:

I. to compare drinking patterns of commercial and private drivers, and

2. to explore the relationship of hazardous drinking with psychological (optimistic bias, perceived drinking norms), environmental (type of neighborhood, proximity to alcohol vendor or point of sale) and demographic (age, education, income) factors and whether this relationship differs for commercial drivers versus private drivers.

\section{Method}

\section{Participants}

Five hundred and sixty-six purposively selected drivers from the Ibadan metropolis participated in this cross-sectional survey. Participants' inclusion criteria included age of at least i 8 years, possession of a valid driver's license, and at least six months of vehicular driving experience prior to the interview. Two categories of drivers were included in the study: commercial and private. Commercial drivers were those who drive com- 
muter buses, cabs and taxis, and operate mainly from different parks within the Ibadan metropolitan area. Private drivers included people who drive their own, friends', spouses', parents' or corporate vehicles. Of the 566 participants, 24I (42.6\%) were commercial drivers and 325 (57.4\%) were private car drivers. In total 489 (86\%) of participants were male and 77 (I4\%) were female. Participants' mean age was 35.70 years (SD 8.62 years). These and other demographic characteristics of the participants are presented in Table I, at the beginning of the Results section.

\section{Measures}

Hazardous drinking was assessed using the World Health Organization's Io-item Alcohol Use Disorders Identification Test (AUDIT) (Babor, HigginsBiddle, Saunders, \& Monteiro, 200I). The AUDIT was developed as a simple instrument to screen for excessive or hazardous drinking and to assist in brief assessment. Based on individuals' composite scores on the AUDIT, their risk levels and the implications for intervention can be assessed. According to the AUDIT manual, a score of zero indicates that the individual is an abstainer; scores of $0-7$ fall into zone I (alcohol education); scores of 8-I5 fall into zone II (simple advice); scores of I6-I9 fall into zone III (simple advice plus brief counseling and continued monitoring); while scores of $20-40$ fall into zone IV (indicating that the individual should be referred to a specialist for diagnostic evaluation and treatment). The AUDIT has been used by researchers in Nigeria and has been shown to display adequate psychometric properties and cultural relevance (Abikoye \& Osinowo, 20II; Akinnawo, 20I0). A Cronbach's alpha coefficient of .76 was obtained for the AUDIT in this study.

Background/demographic variables: Respondents were asked their age, gender, education, job status and driver status (private or commercial). Respondents were requested to indicate their estimated average monthly income by choosing one of the six options ranging from "Less than 10,000 naira" to "Iо०,००० naira or more."

Optimistic bias was assessed with the Life Orientation Test-Revised (LOT-R) (Scheier et al., I994). The LOT-R provides continuous distributions of scores on the extent to which people are optimistic or pessimistic. The 6 item instrument is scored using a 5-point scale ranging from "I agree a lot" (4) to "I disagree a lot" (0). The 6 items on the scale are framed with 3 in each direction. The
LOT-R has good internal consistency, with Cronbach's alpha in the high .70s to .80s, and is quite stable over time (Scheier et al., I994). In this study, the Cronbach's alpha coefficient was .78.

Perceived drinking norm was assessed using the adapted (Brody et al., I998) I2-item Perceived Norms about Substance Use scale. Each item is scored along a 5-point scale ranging from "totally acceptable" to "totally unacceptable," with higher scores indicating that a respondent perceives drinking to be normal for him or her. A Cronbach's alpha coefficient of .8I was obtained for the scale in this study.

Environmental variables. Proximity to an alcohol vendor or selling point ("joint” or "beer parlour") was assessed by asking respondents to indicate whether any such outlet is located "on the same street" in which they reside (scored as 3), on the "next street" (2), "a few streets away" (I), or "not available in my neighborhood" (o). Participants were further requested to indicate their areas of residence, which were classified as either "high density" or "low density" based on Oyo state government official classification.

\section{Procedure}

The survey was carried out in Ibadan, a large metropolitan city in southwestern Nigeria, during the third quarter of 2010. Locations were selected based on availability of the targeted population. Commercial drivers were interviewed at car parks while on "turn" (queue) to collect their passengers, and at car wash centers and automobile workshops (where electrical and mechanical repairs on cars and other automobiles are carried out) across the city. Private drivers were interviewed at car wash centers and automobile workshops across the city. Participation was voluntary and informed consent was obtained by participants' signing the consent form attached to the questionnaire. Since all participants were literate, with at least some high school education, there was no problem with completion of the questionnaire. Participants were instructed not to indicate their names anywhere on the survey materials. No financial incentive was given to participants. The researcher and two graduate-level assistants personally administered the research questionnaire over a four-month period, during which 566 copies of the 600 questionnaires administered were returned with usable data, representing a $94 \%$ return rate. 


\section{Results}

Descriptive statistics and significance of differences between commercial and private drivers are shown in Table I. There were no significant age or marital status differences between the two samples. However, there were significant differences between the samples in terms of sex, employment, estimated monthly income, education and type of neighborhood. Specifically, while all the commercial drivers were males, $76.0 \%$ the private drivers were males and $24.0 \%$ were females $\left(\chi^{2}=67.3 ; \mathrm{p}<.0 \mathrm{I}\right)$. With regards to formal educational attainment, while I9.5\% of the commercial drivers had less than high school education, only $6.2 \%$ of the private drivers reported a similar level of education. At the other extreme, while only $3.3 \%$ of the commercial drivers possessed a university first degree or its equivalent, $38.7 \%$ of the private drivers possessed a university first degree or its equivalent $\left(\chi^{2}=\mathrm{I} 63.3 ; \mathrm{p}<. .00 \mathrm{I}\right)$. Differences also existed in terms of neighborhood, with more private drivers residing in low density areas $(39.4 \%)$, compared to $24.1 \%$ of the commercial drivers $\left(\chi^{2}=\mathrm{I} 4.92 ; \mathrm{p}<.0 \mathrm{I}\right)$.

Table 1

Descriptive characteristics by drivers' status

\begin{tabular}{|c|c|c|c|c|}
\hline Variable & $\begin{array}{c}\text { Commercial drivers } \\
(\mathrm{N}=\mathbf{2 4} \mathrm{I}) \\
\end{array}$ & $\begin{array}{c}\text { Private drivers } \\
(\mathrm{N}=325)\end{array}$ & $\begin{array}{c}\text { Total sample } \\
(\mathrm{N}=566)\end{array}$ & $\chi^{2}$ \\
\hline \multicolumn{5}{|l|}{ Gender (\%) } \\
\hline Males & 100.0 & 76.0 & 86.2 & $67.3 * * * *$ \\
\hline Females & - & 24.0 & 13.8 & \\
\hline Age $(\mathrm{M} \pm \mathrm{SD})$ & $39.3 \pm 6.3$ & $33.4 \pm 7.3$ & $35.7 \pm 8.6$ & 0.5 \\
\hline \multicolumn{5}{|l|}{ Marital status (\%) } \\
\hline Single & 31.1 & 27.1 & 28.8 & $266.1 * * *$ \\
\hline Married & 41.9 & 47.6 & 44.9 & \\
\hline Divorced/separated/widowed & 27.0 & 25.3 & 26.3 & \\
\hline \multicolumn{5}{|l|}{ Employment (\%) } \\
\hline Working for pay & - & 47.1 & 27.0 & \\
\hline Commercial drivers & 100.0 & 0.0 & 42.6 & \\
\hline Self-employed & - & 32.0 & 18.4 & \\
\hline Unemployed & - & 8.0 & 4.6 & \\
\hline Students & - & 12.9 & 7.4 & $5.47 *$ \\
\hline \multicolumn{5}{|l|}{ Estimated monthly income (\%) } \\
\hline Less than $\mathrm{N} 20,000$ & 36.1 & 28.9 & 31.9 & \\
\hline $\mathrm{N} 20,000-\mathrm{N} 65,000$ & 58.9 & 62.2 & 60.8 & \\
\hline N65,001 and above & 5.0 & 8.9 & 7.3 & $163.3 * * *$ \\
\hline \multicolumn{5}{|l|}{ Education (\%) } \\
\hline Less than high school & 19.5 & 6.2 & 11.8 & \\
\hline High school & 63.1 & 24.0 & 40.6 & \\
\hline Diploma or equivalents & 14.1 & 31.1 & 23.9 & \\
\hline First degree or higher & 3.3 & 38.7 & 23.7 & $14.92 * *$ \\
\hline \multicolumn{5}{|l|}{ Type of neighborhood (\%) } \\
\hline High density & 75.9 & 60.6 & 68.3 & \\
\hline Low density & 24.1 & 39.4 & 31.7 & \\
\hline Proximity $(\mathrm{M} \pm \mathrm{SD})$ & $2.8 \pm 1.3$ & $2.1 \pm 1.5$ & $2.4(1.5)$ & 0.1 \\
\hline Perceived drinking norm $(\mathrm{M} \pm \mathrm{SD})$ & $47.1 \pm 6.3$ & $38.2 \pm 7.3$ & $42.7 \pm 6.3$ & 1.0 \\
\hline Optimistic bias $(\mathrm{M} \pm \mathrm{SD})$ & $22.6 \pm 5.3$ & $21.3 \pm 4.8$ & $21.9 \pm 5.0$ & 0.1 \\
\hline Hazardous drinking $(\mathrm{M} \pm \mathrm{SD})$ & $26.4 \pm 5.2$ & $21.1 \pm 6.8$ & $23.8 \pm 5.4$ & 0.6 \\
\hline
\end{tabular}

$* \mathrm{p}<.05 ; * * \mathrm{p}<.01 ; * * * \mathrm{p}<.001$

The prevalence of hazardous drinking for commercial and private drivers is presented in Table 2. A high rate of hazardous drinking was found for both groups. While abstainers in the two groups appeared to be similar in proportion, private drivers are found more in the second category of hazardous drinking relative to commercial drivers, while commercial drivers were more likely to score in the highest zone. 
Table 2

Hazardous drinking (AUDIT score) by driver category

\begin{tabular}{|c|c|c|c|c|c|c|}
\hline \multirow[b]{2}{*}{ Risk level (AUDIT score) } & \multicolumn{2}{|c|}{ Commercial drivers } & \multicolumn{2}{|c|}{ Private drivers } & \multirow[b]{2}{*}{ df } & \multirow[b]{2}{*}{$\chi^{2}$} \\
\hline & $\mathbf{N}$ & $\%$ & $\mathbf{N}$ & $\%$ & & \\
\hline Abstainers $(0)$ & 21 & 8.7 & 28 & 8.6 & & \\
\hline Zone I (1-7) & 49 & 20.3 & 67 & 20.6 & 9 & $34.51 * *$ \\
\hline Zone II (8-15) & 62 & 25.7 & 148 & 45.5 & & \\
\hline Zone III (16-19) & 81 & 33.6 & 70 & 21.5 & & \\
\hline Zone IV (20+) & 28 & 11.6 & 12 & 3.7 & & \\
\hline
\end{tabular}

Table 3 presents the correlation matrix for the variables in the study: age, education, income, proximity to alcohol sale point or vendor, type of neighborhood, optimistic bias, perceived drinking norms and hazardous drinking (AUDIT scores) for commercial and private drivers. Sex was excluded because the commercial drivers sample consisted of only males. Most of the correlation coefficients are significant and the patterns of association are similar for commercial and private drivers.

In addition, all the variables displayed very strong associations with hazardous drinking for both groups.

Table 3

Correlation among age, education, income, proximity to alcohol, neighborhood density, perceived drinking norm, optimistic bias and hazardous drinking for commercial and private drivers

\begin{tabular}{|c|c|c|c|c|c|c|c|}
\hline & Age & Education & $\begin{array}{l}\text { Income } \\
\text { Comm }\end{array}$ & $\begin{array}{l}\text { Proximity } \\
\text { rcial drivers }\end{array}$ & $\begin{array}{l}\text { Neighborhood } \\
\text { density }\end{array}$ & $\begin{array}{c}\text { Perceived } \\
\text { drinking norm }\end{array}$ & $\begin{array}{c}\text { Optimistic } \\
\text { bias }\end{array}$ \\
\hline Age & & & & & & & \\
\hline Education & $-.28 *$ & - & & & & & \\
\hline Income & $-.24 *$ & $.25 *$ & - & & & & \\
\hline Proximity & .11 & .08 & $-.23 *$ & - & & & \\
\hline $\begin{array}{l}\text { Neighborhood } \\
\text { density }\end{array}$ & .13 & $-.23 *$ & $.22 *$ & $.37 * *$ & - & & \\
\hline $\begin{array}{l}\text { Perceived drinking } \\
\text { norm }\end{array}$ & $-.24 *$ & $-.27 *$ & .11 & $.34 * *$ & $.28 *$ & - & \\
\hline Optimistic bias & $-.26 *$ & .15 & .11 & $.36 * *$ & $.36 * *$ & $.30 * * *$ & \\
\hline Hazardous drinking & $-.25 *$ & $-.37 * *$ & $-.36 * * *$ & $.43 * *$ & $.33 * *$ & $.39 * *$ & $.34 * *$ \\
\hline \multicolumn{8}{|c|}{ Private drivers } \\
\hline Age & - & & & & & & \\
\hline Education & $-.23 *$ & - & & & & & \\
\hline Income & $-.21 *$ & $.27 *$ & - & & & & \\
\hline Proximity & .07 & $-.28 *$ & $-.29 *$ & - & & & \\
\hline $\begin{array}{l}\text { Neighborhood } \\
\text { density }\end{array}$ & $.23 \%$ & $.26 *$ & $.26^{*}$ & $.27 *$ & - & & \\
\hline $\begin{array}{l}\text { Perceived drinking } \\
\text { norm }\end{array}$ & $-.27 *$ & $.24 *$ & .13 & $.31 * *$ & $.38 * *$ & - & \\
\hline Optimistic bias & $-.23 *$ & $.22 *$ & $-.19 *$ & $.31 * *$ & $.26 *$ & $.27 *$ & \\
\hline Hazardous drinking & $-.31 *$ & $-.27 *$ & $-.31 * *$ & $.36 \%$ & $.37 * *$ & $.31 * *$ & $.36 * *$ \\
\hline
\end{tabular}

$\mathrm{p}<.05 ; * * \mathrm{p}<.01$

Age, education, income, proximity, perceived drinking norm, optimistic bias and hazardous drinking were scored in the positive direction. Neighborhood density: low density area was coded as 1 ; high density area was coded as 2 . 
Table 4 presents the results of the stepwise multiple regression analyses, showing the extent to which each of the three clusters of variables in the study predicted hazardous drinking. The first step shows the results of demographic variables (age, education and income) only; the second step shows the additional impact of psychological variables (optimistic bias and perceived drinking norms); and the third step shows the results when environmental factors (proximity and type of neighborhood) were added. The results of the first step show that age, education and income contributed about $15 \%$ of the explained variances in hazardous drinking among commercial drivers and $14 \%$ among private drivers.

\section{Table 4}

Beta coefficients from stepwise multiple regression of hazardous drinking on demographic, environmental and psychological variables for commercial and private drivers

\begin{tabular}{|c|c|c|c|}
\hline Variable & Step 1 & Step 2 & Step 3 \\
\hline \multicolumn{4}{|c|}{ Commercial drivers } \\
\hline Age & $-.19 *$ & $-.17 *$ & $-.17 *$ \\
\hline Education & $-.16^{*}$ & $-.14 \%$ & $-.13 \%$ \\
\hline Income & $-.16^{*}$ & $-.14 *$ & -.11 \\
\hline Optimistic bias & & $.21 *$ & $.21 *$ \\
\hline Perceived drinking norms & & $.29 * *$ & $.18 *$ \\
\hline Proximity to alcohol outlets & & & $.22 * *$ \\
\hline Neighborhood density & & & $.26 * *$ \\
\hline$R$ & .41 & .57 & .67 \\
\hline$R^{2}$ & .16 & .33 & .46 \\
\hline Adj. $R^{2}$ & .15 & .32 & .44 \\
\hline$R^{2}$ change & & .17 & .13 \\
\hline$F$ change & & $8.93 * *$ & $7.33 * *$ \\
\hline \multicolumn{4}{|c|}{ Private drivers } \\
\hline Age & $-.16 *$ & $-.13 *$ & $-.13 *$ \\
\hline Education & $-.16^{*}$ & $-.12 *$ & $-.13 *$ \\
\hline Income & $-.17 *$ & $-.13 *$ & $-.14 *$ \\
\hline Optimistic bias & & $.23 * *$ & $.27 * *$ \\
\hline Perceived drinking norms & & $.26^{* * *}$ & $.29 * * x$ \\
\hline Proximity to alcohol outlets & & & $.17 *$ \\
\hline Neighborhood density & & & $.26 * *$ \\
\hline$R$ & .38 & .53 & .68 \\
\hline$R^{2}$ & .15 & .28 & .46 \\
\hline Adj. $R^{2}$ & .14 & .27 & .45 \\
\hline$R^{2}$ change & & .13 & .18 \\
\hline$F$ change & & $11.25^{* *}$ & $6.07 * *$ \\
\hline
\end{tabular}

Step 1 included demographic variables (age, education and income) as predictors. Step 2 included both demographic and psychological (optimistic bias and perceived drinking norms) variables. Step 3 included demographic, psychological and environmental (proximity to alcohol outlets and neighborhood density) variables. Standardized regression coefficients are reported.

$* \mathrm{p}<.05 ; * * \mathrm{p}<.01$

The second step-the additional impact of psychological factors in predicting hazardous drinking-shows the two variables contributing an additional $17 \%$ of explained variances for commercial drivers and an additional $13 \%$ of explained variances for private drivers. For both commercial and private drivers, therefore, optimistic bias and perceived drinking norms add a significant amount of explained variances to hazardous drinking. Results of the third step-the additional impact of environmental variables-indicate that proximity to alcohol outlets and neighborhood density contributed additional $13 \%$ and $18 \%$ explained variances in hazardous drinking for commercial drivers and private drivers, respectively. Thus, the entry of the additional variables significantly improved the variance accounted for in both samples. Overall, all the variables considered in this study explained $44 \%$ of the 
variances in hazardous drinking for commercial drivers and $45 \%$ for private drivers.

\section{Discussion}

This study investigated hazardous drinking among drivers and the extent to which some demographic (age, education, income), environmental (proximity to alcohol outlets, neighborhood density) and psychological (optimistic bias, perceived drinking norms) variables predicted hazardous drinking for commercial drivers and private drivers. Consistent with earlier studies among drivers in Nigeria (Abiona et al., 2006; Makanjuola et al., 2007), the results of this study indicate that alcohol consumption is quite high among drivers in Ibadan. Contrary to the widely held notion that hazardous drinking is a problem among only commercial drivers in Nigeria, findings in the study revealed that private drivers also reported high levels of hazardous drinking. Although more commercial drivers scored as hazardous drinkers on the AUDIT $145 \%$ of commercial drivers versus $25 \%$ of private drivers), there was still a substantial proportion of private drivers who reported hazardous levels of consumption.

The prediction of alcohol use by education and income may be due to individuals with higher education and income being more aware of the deleterious effects of excessive alcohol use and excessive drinking. People with higher education and income are also likely to be more sensitive to evaluations from their social world, compared to individuals with low education and income.

Higher perceived drinking norms and optimistic bias were also associated with hazardous drinking scores. These findings are consistent with previous empirical evidence in other countries (Allison et al., I999; Case, I99I; Crum et al., I996; Karvonen \& Harja, I997). The prediction of alcohol use by perceived optimistic bias is supported by previous studies in other countries (Gibbons et al., 2003; Scheier et al., I997), which found that if people underestimate their risk of experiencing a negative health outcome, they will be less likely to take precautions to prevent that outcome from occurring. Thus, given that optimistic bias represents an underestimation of risk, it may be argued that such a bias is maladaptive and may help explain why drivers drink alcohol. Perceiving others as more at risk than oneself has also been linked to greater likelihood of engaging in detrimental behaviors.

Environmental factors were significantly associated with hazardous drinking, with proximity to alcohol outlets and neighborhood density both significantly associated with hazardous drinking when other variables were controlled for in regression models. That is, the closer a driver resided to an alcohol sale point, the more likely he or she was to engage in hazardous drinking. Drivers who resided in low-density areas were less likely to drink compared to those who resided in high-density areas. With regards to the finding that respondents who resided in high-density areas were more likely to be involved in hazardous drinking compared with those from low-density areas, a plausible explanation is that drinking behavior is more socially accepted in high-density areas and there may be more opportunities for drinking and developing a hazardous drinking pattern.

There are important implications of the findings of this study for preventing vehicular accidents. First, drivers' alcohol consumption could be discouraged by government through appropriate legislation and empowering relevant agencies with equipment, personnel and other resources to help them apprehend and prosecute offenders. Second, attention should not be restricted to commercial drivers only. Since results indicated that private drivers are also involved in hazardous drinking and given the fact that there are more private drivers than commercial drivers in Nigeria, the greatest effect will be achieved by focusing on both commercial and private drivers. Another implication is that hazardous consumption is associated with proximity of alcohol outlets, and so prohibiting sale of alcohol in motor parks, garages and along highways could have a substantial impact on reducing alcohol-related vehicular accidents.

There are several limitations of this study. First, the factors considered are not in any way exhaustive, and there are other possible explanations for the problem of hazardous drinking among drivers. Second, the study was a cross-sectional survey and participants were selected using a purposive sampling technique. Therefore, the extent that environmental and psychological variables measured in the study contribute to hazardous drinking is not known from these analyses. In addition, it should be noted that the samples in this study may not necessarily typify the overall population of drivers in Ibadan or other Nigerian cities. Future research efforts should address these issues to provide more 
robust explanations of predictors of hazardous drinking among drivers.

\section{References}

Abdelrahaman, A. I., Rodriguez, G., Ryan, J., French, F., \& Wembaum, D. (I998). The epidemiology of substance use among middle school students: The impact of school, familial, community and individual risk factors. Journal of Child \& Adolescent Substance Abuse, 8, 55-75.

Abikoye, G. E., \& Adekoya, J. A. (20I0). Predicting substance abuse in a sample of Nigerian undergraduates: The role of core self-evaluations and delay of gratification. Psychological Studies, 55, 299-307.

Abikoye, G. E., \& Osinowo, H. O. (20II). In the eye of the beholder: Alcohol use and perceptions among student-patrons of joints in three Nigerian university communities. Psychological Studies, 56, 258-265.

Abiona, T. C., Aloba, O. O., \& Fatoye, F. O. (2006). Patterns of alcohol consumption among commercial road transport workers in a semi-urban community in south-western Nigeria. East African Medical Journal, 83, 494-499.

Akinnawo, E. O. (2010, Nov I5-I9). Alcohol-related traffic risk behaviours of selected commercial drivers in Nigeria. Paper presented at the KBS Thematic Meeting on Alcohol Epidemiology and Policy, Kampala, Uganda.

Allison, K. W., Crawford, I., Leone, P. E., Trickett, E., Perez-Febles, A., Burton, L. M., \& Le Blanc, R. (I999). Adolescent substance use: Preliminary examination of school and neighborhood context. American Journal of Community Psychology, 27, III-I4I.

Aworemi, J. R., Abdul-Azeez, I. A., \& Olabode, S. O. (20I0). Analytical study of the causal factors of road traffic crashes in south western Nigeria. Educational Research, 1, I18-I24.

Babor, T. F., Higgins-Biddle, J. C., Saunders, J. B., \& Monteiro M. G. (200I). The Alcohol Use Disorders Identification Test: Guidelines for use in primary care (2nd Ed.). Geneva, Switzerland: World Health Organization.

Brody, G. H., Flor, D. L., Hollett-Wright, N., \& Mccoy, J. K. (I998). Children's development of alcohol use norms: Contributions of parent and sibling norms, children's temperaments, and parent-child discussions. Journal of Family Psychology, 12, 209-2I9.
Case, A.C. (I99I). The company you keep: The effect of family and neighborhood on disadvantaged youth. NBER Working Paper No. 3705. Cambridge, U.S.A.: National Bureau of Economic Research. Retrieved from http://www.nber.org.

Coleman, J. S. (1988). Social capital in the creation of human capital. American Journal of Sociology, 94, S95-Si20.

Crum, R. M., Lillie-Blanton, M., \& Anthony, J. C. (I996). Neighborhood environment and opportunity to use cocaine and drugs in late childhood and early adolescence. Drug and Alcohol Dependence, 43, I55-I6I.

Gibbons, F. X., Gerrard, M., \& Lane, D. J. (2003). A social reaction model of adolescent health risk. In J. M. Suls, \& K. A. Wallston, (Eds.), Social psychological foundations of health and illness, (pp. I07-136). Malden, U.S.A.: Blackwell.

Global Actions on Harmful Drinking. (20II). Addressing the drinking and driving phenomenon in Nigeria [Fact sheet]. Retrieved from http://www.global-actions.org.

Gureje, O., Degenhardt, L., Olley, B. O., Uwakwe, R., Udofia, O., Wakil, A., Adeyemi, O., Bohnert, K. M., \& Anthony J. C. (2007). A descriptive epidemiology of substance use and substance use disorders in Nigeria during the early 2ist century. Drug and Alcohol Dependence, 91, I-9.

Gururaj, G. (2004). Alcohol and road traffic injuries in South Asia: Challenges for prevention. Journal of the College of Physicians and Surgeons (Pakistan), 14, 713-7I8.

Hibell, B., Guttornsson, U., Ahlstrom, S., Balakireva, O., Bjarnason, T., Kokkevi, A., \& Kraus, L. (2009). The 2007 ESPAD report: Substance use among students in 35 European countries. Stockholm, Sweden: Swedish Council for Information on Alcohol and Other Drugs.

Karvonen, S., \& Harja, H. R. (I997). Urban small area variation in adolescent health behaviour. Social Science \& Medicine, 45, 1089-1098.

Makanjuola, B. A., Oyeleke, S. A., \& Akande, T. M. (2007). Psychoactive substance use among long distance vehicle drivers in Ilorin, Nigeria. Nigerian Journal of Psychiatry, 5, I4-I8.

Omolase, C. O., Afolabi, O. T., Omolase, B. O., \& Ihemedu, C. O. (2OII). Drink-driving among commercial drivers in a Nigerian community. Middle East Journal of Psychiatry and Alzheimer's, 2, I5-I9.

Owoaje, E. T., Amoran, O. E., Osemeikhain, O., \& 
Ohnoferi, O. E. (2005). Incidence of road traffic accidents and pattern of injury among commercial motorcyclists in a rural community in South Western Nigeria. Journal of Community Medicine and Primary Health Care, I7, 7-I2.

Scheier, M. F., Carver, C. S., \& Bridges, M. W. (1994). Distinguishing optimism from neuroticism (and trait anxiety, self-mastery, and self-esteem): A re-evaluation of the life orientation test). Journal of Personality and Social Psychology, 67, 1063-1078.

Shaw, C. R., \& Mckay, H. R. D. (1969). Juvenile delinquency and urban areas: A study of rates of delinquency in relation to differential characteristics of local communities in American cities. Chicago, U.S.A.: The University of Chicago Press.

Siziya, S., Rudatsikira, E., \& Muula, A. S. (2009). Alcohol use among school-going adolescents in Harare, Zimbabwe: Results from the 2003 Global School-Based Health Survey. Tanzania Journal of Health Research, 11, II-I6.

Welcome, M. O., \& Pereverzev, V. A. (2010). Limit of blood alcohol concentration: A major problem to solve in Nigeria. European Psychiatry, 25(Suppl I), 544 .

Wilson, W.I. (1987). The truly disadvantaged: The inner city, the underclass and public policy. Chicago, U.S.A.: University of Chicago Press.

World Health Organization. (2009). Global status report on road safety: Time for action. Geneva, Switzerland: Author.

World Health Organization. (2004). World report on road traffic injury prevention. Geneva, Switzerland: Author. 